\title{
SALÁRIO MINÍMO NACIONAL VS PRINCÍPIO DA DIGNIDADE DA PESSOA HUMANA
}

Mayara Aparecida Assumpção Ribeiro, Francislaine de Almeida Coimbra Strasser

Universidade do Oeste Paulista - UNOESTE, Curso de Direito, Presidente Prudente, SP. E-mail: maya28assupcao@gmail.com

\section{RESUMO}

A presente pesquisa tem por finalidade reflexionar acerca do salário mínimo nacional adotado hodiernamente como parâmetro mínimo para fins de remuneração à luz do artigo 7으, inciso IV da Constituição Federal de 1988, prevendo que o salário mínimo seja capaz de proporcionar ao empregado, instituindo importância incapaz resguardar ao indivíduo o mínimo básico, necessário para sua sobrevivência e de sua família, desprezando nitidamente o princípio basilar de um Estado Democrático de Direito, ou seja, o princípio da Dignidade da Pessoa Humana. Para que a pesquisa desenvolva-se de modo adequado adotou-se o método hipotético-dedutivo, realizado através de pesquisa bibliográfica, com a utilização de doutrina, jurisprudência, artigos eletrônicos e textos normativos, infraconstitucional e constitucional. Após refletir sobre o tema abordado, conclui-se que o salário mínimo nacional estabelecido em lei mostra-se completamente incapaz de atender as necessidades vitais básicas dos trabalhadores, assim como a de sua prole.

Palavras-chaves: Empregado. Vida digna. Salário mínimo. Subsistência.

\section{NATIONAL MINIATURE WAGE VS PRINCIPLE OF THE DIGNITY OF THE HUMAN PERSON}

\begin{abstract}
The aim of the present research is talking about the national minium wage and measures adopted in article 7, IV of the Federal Constitution of 1988 that provides the necessary to survive. The minium wage actual is not able to assign the employee the delivering economic prosperity and his family, besides the social justice. That wage display completing disregard forhuman dignity, against of dignity of their life. For this research was adopted the deductive hypothetical method through bibliographical research, using doctrine, jurisprudence, electronic articles and normative, constitutional texts. After reflecting on the topic addressed, it is concluded that the national minimum wage established by law not is completely able of meeting the basic vital needs of workers, as well as that of their children.
\end{abstract}

Keywords: Employee. Life worthy. Minimum wage. Selfreliance. 


\section{INTRODUÇÃO}

A presente pesquisa tem por finalidade refletir acerca da efetividade do salário mínimo nacional vigente no qual contrapõe ao mínimo existencial fundamentado à luz do princípio da Dignidade da Pessoa Humana, positivado em nossa Magna Carta como um dos fundamentos da República Federativa do Brasil.

Observa-se que o legislador originário prevê hipoteticamente que o salário mínimo nacional, seja capaz de proporcionar a um trabalhador, condições financeiras adequadas para que indivíduo seja capaz de atender suas necessidades básicas, não apenas para sua sobrevivência, mas também de sua prole, ferindo assim o princípio basilar de um Estado Democrático de Direito, ou seja, o princípio da Dignidade da Pessoa Humana consagrado no artigo 1으, inciso III da Constituição Federal de 1988.

O objetivo da presente pesquisa é salutar no sentido de produzir um conhecimento que sirva de estímulo para a realização de novas pesquisas pelos acadêmicos das ciências jurídicas e afins propiciando assim uma melhor compreensão acerca da ineficácia e insuficiência do salário mínimo nacional frente ao princípio da dignidade da pessoa humana, assim como o mínimo existencial.

Contribui assim, nos limites próprios da dogmática jurídica, para a superação do fosso existente entre as generosas disposições jusfundamentais da Constituição de 1988 e as imensas carências materiais de grande parte dos brasileiros.

\section{METODOLOGIA}

Para que a pesquisa desenvolva-se de modo adequado adotou-se o método hipotéticodedutivo, realizado através de pesquisa bibliográfica, com a utilização de doutrina, jurisprudência, artigos eletrônicos e textos normativos, infraconstitucional e constitucional.

\section{DOS DIREITOS DO EMPREGADO}

O trabalhador brasileiro, ao celebrar um contrato de emprego, assume as incumbências de tal contrato, sendo eles os deveres e direitos inerentes ao pacto realizado, ou seja, ao contrato de trabalho.

Inicialmente, faz-se necessário, realizar breves apontamentos relativos à relação empregatícia. Segundo Mauricio Godinho Delgado, (2016, p. 300), a Consolidação das Leis do Trabalho em seu artigo 3으, traz os elementos caracterizadores da relação empregatícia sem os quais não se configura a mencionada relação. Senão vejamos:

Art. 3o - Considera-se empregado toda pessoa física que prestar serviços de natureza não eventual a empregador, sob a dependência deste e mediante salário (BRASIL, 1943).

A doutrina extrai do referido diploma legal, que para caracterizar o vínculo empregatício e fazer jus aos seus direitos, o empregado devera preencher todos os requisitos, ou seja, subordinação, habitualidade, pessoalidade e onerosidade. (DELGADO, 2016, p. 301-310).

Salta aos olhos, que quando a doutrina menciona o elemento onerosidade, este se refere diretamente ao salário, um dos principais direitos assegurados ao trabalhador. O que será o objeto principal deste estudo.

Observa-se que o legislador preocupou-se em seguir os preceitos constitucionais, estabelecendo assim, na própria Consolidação das Leis do Trabalho, que ao empregado será pago a titulo de contraprestação o salário, este observado ao salário mínimo, senão vejamos:

Art. 76 - Salário mínimo é a contraprestação mínima devida e paga diretamente pelo empregador a todo trabalhador, inclusive ao trabalhador rural, sem distinção de sexo, por dia normal de serviço, e capaz de satisfazer, em determinada época e região do País, as suas necessidades normais de alimentação, habitação, vestuário, higiene e transporte (BRASIL, 1943). 
Deste modo, nota-se que a todo empregado trabalhador em virtude dos serviços laborais prestados, este fará jus ao direito de perceber no mínimo um salário a título de contraprestação. Entretanto, indaga-se se o salário mínimo vigente mostra-se suficientemente capaz de suprir as necessidades básicas e essências de um trabalhador.

É cediço que a resposta será negativa. Mas, o que se verifica é que apesar da ideia do salário mínimo atender a finalidade distinta daquela visada pelo direito ao mínimo existencial, tal norma supramencionada da CLT permite estabelecer as bases do que se considera hoje, numa sociedade brasileira, impensável para uma existência digna: alimentação, moradia, saúde básica, vestuário, além do acesso à Justiça, direito instrumental indispensável à eficácia dos direitos fundamentais.

A partir desses parâmetros do conteúdo do mínimo existencial chega-se em cada caso das necessidades do indivíduo que o componham e o patamar de sua satisfação que se considere suficiente para assegurar o respeito à dignidade.

\section{O MÍNIMO EXISTENCIAL}

Conforme se observou outrora, aos indivíduos que se encontram vinculados a uma relação empregatícia, deverão perceber a título de contraprestação o mínimo de um salário vigente, salvo as hipóteses previstas em lei que possibilita o indivíduo de perceber créditos inferiores ao mínimo legal, desde que na sua proporcionalidade, sendo indispensável para uma existência digna.

Assim, manter uma existência digna é dar as condições para que o ser humano não perca a capacidade de autodeterminar-se e de ser sujeito.

Esse patamar de conteúdo mínimo, objetivando assegurar a qualidade do indivíduo, teve por referência ao artigo XXV da Declaração Universal dos Direitos do Homem de 1948, o qual propicia a todos os seres humanos e seus familiares o direito a uma qualidade de vida minimamente digna Ihes sejam conferindo o direito a saúde, alimentação, habitação, vestuário e serviços de previdência social. Senão vejamos:

\section{Artigo XXV}

1. Todo ser humano tem direito a um padrão de vida capaz de assegurar-Ihe, e a sua família, saúde e bem-estar, inclusive alimentação, vestuário, habitação, cuidados médicos e os serviços sociais indispensáveis, e direito à segurança em caso de desemprego, doença, invalidez, viuvez, velhice ou outros casos de perda dos meios de subsistência em circuns tâncias fora de seu controle. (IORQUE, 1948).

Observa-se que o legislador originário da República Federativa do Brasil, em observância a Declaração Universal dos Direitos Humanos de 1948, estabeleceu em nossa Magna Carta de 1988 o artigo 70, inciso IV, assegurando tudo o que previa a mencionada declaração, abaixo transcrito.

Art. 70 São direitos dos trabalhadores urbanos e rurais, além de outros que visem à melhoria de sua condição social:

IV - salário mínimo, fixado em lei, nacionalmente unificado, capaz de atender a suas necessidades vitais básicas e às de sua família com moradia, alimentação, educação, saúde, lazer, vestuário, higiene, transporte e previdência social, com reajustes periódicos que the preservem o poder aquisitivo, sendo vedada sua vinculação para qualquer fim (BRASIL, 1988).

Retornando a indagação realizada anteriormente, visto que no texto constitucional previu que o salário mínimo, atualmente estipulado em novecentos e cinquenta e quatro reais, fixado em lei é capaz de atender as necessidades vitais básicas do trabalhador e de sua família, percebe-se que não assegura uma existência digna, chocando-se com o princípio da dignidade humana.

Isso porque o direito ao mínimo para uma existência digna, conforme bem explica Eurico Bitencort Neto, (2010) é um direito sobre direitos, pois não possui conteúdo próprio distinto e 
complementar dos demais direitos fundamentais, mas é um direito do cumprimento do mínimo de outros direitos fundamentais, especialmente o da dignidade, da igualdade material e da solidariedade social.

Garantir o mínimo existencial é o mesmo que salvaguardar a dignidade do ser humano, numa efetividade da igualdade almejada e assim alcançaria a solidariedade social.

\section{PRINCÍPIO DA DIGNIDADE DA PESSOA HUMANA}

O princípio da dignidade da pessoa humana é o principal fundamento do nosso ordenamento pátrio, segundo prevê expressamente a CR/88 (art. 1으, III), vinculando assim todo o ordenamento jurídico.

Art. 1ㅇ A República Federativa do Brasil, formada pela união indissolúvel dos Estados e Municípios e do Distrito Federal, constitui-se em Estado Democrático de Direito e tem como fundamentos:

III - a dignidade da pessoa humana (BRASIL, 1988).

Como já mencionado precedentemente, a dignidade da pessoa humana é o valor supremo a ser buscado pelo ordenamento jurídico, é o princípio basilar a partir do qual decorrem todos os demais direitos fundamentais.

Neste sentido leciona Flademir Jerônimo Belinati Martins (2011, p.58-59):

Os valores traduzem-se, assim, em ideias diretivas gerais que fundamenta, orientam e limitam criticamente a interpretação e aplicação das demais normas do ordenamento jurídico, sem, contudo, especificar os supostos em que devem ser aplicados nem as consequências jurídicas que se lhes devem seguir.

Tem-se assim que além de ser um princípio foi consagrada como fundamento do Estado Democrático de Direito, bem como o vetor, alicerce, a base de onde se emanam todos os demais princípios.

Ingo Wolfgang Sarlet bem define a dignidade da pessoa humana (2015, p.70):

Temos por dignidade da pessoa humana a qualidade intrínseca e distintiva de cada ser humano que o faz merecedor do mesmo respeito e consideração por parte do Estado e da comunidade, implicando, neste sentido, um complexo de direitos e deveres fundamentais que assegurem a pessoa tanto contra todo e qualquer ato de cunho degradante e desumano, como venham a lhe garantir as condições existenciais mínimas para uma vida saudável, além de propiciar e promover sua participação ativa corresponsável nos destinos da própria existência e da vida em comunhão com os demais seres humanos.

No mesmo sentido, Flávia Piovesan leciona que (2004, p. 92):

É no valor da dignidade da pessoa humana que a ordem jurídica encontra seu próprio sentido, sendo seu ponto de partida e seu ponto de chegada, na tarefa de interpretação normativa. Consagra-se, assim, dignidade da pessoa humana como verdadeiro super princípio a orientar o Direito Internacional e o Interno.

Assim, constata-se que a dignidade da pessoa humana não é, no âmbito do Direito, só o ser humano, mas sim o centro de imputação jurídica, valor supremo da ordem jurídica (SILVA, 1998, p.89).

Deste modo, é possível ratificar que esse princípio é o principio mor de um Estado Democrático de Direito, devendo os demais princípios fundamentar-se no princípio basilar. Sendo, portanto, dever do Estado assegurar meios para que todos tenham um mínimo de recursos para que a dignidade de cada um não seja desrespeitada. 


\section{CONSIDERAÇÕES FINAIS}

Ante todo o exposto, conclui-se que embora o legislador originário tenha efetivamente observado o princípio da Dignidade da Pessoa Humana, ao prever que o salário mínimo a ser percebido pelo trabalhador deveria ser suficiente para assegurar existência digna, verificou-se que o salário mínimo é insuficiente para que um único trabalhador sobreviva de forma digna, tampouco para que um trabalhador satisfaça as necessidades de sua família, ferindo drasticamente o princípio mor.

Deste modo, contata-se que o disposto no artigo 70, inciso IV da Constituição Federal de 1988, é completamente ineficaz, incapaz de proporcionar com o salario mínimo nacional vigente todo o rol exemplificativo de necessidades vitais de um indivíduo e sua prole.

Assim, aponta-se que a partir do momento que o Estado não oferece condições mínimas para que sejam concretizados os direitos mínimos existenciais, ele não está dando o devido valor ao Princípio basilar do nosso Estado Democrático, o qual seja o Princípio da Dignidade da Pessoa Humana.

\section{REFERÊNCIAS}

BITENCOURT NETO, Eurico. O direito ao mínimo para uma existência digna. - Porto Alegre: Livraria do Advogado. Editora, 2010.

BRASIL, República Federativa do. Constituição federal de 1988. Promulgada em 5 de outubro de 1988.

Disponível

em

<http://www.planalto.gov.br/ccivil_03/constituicao/constituição.htm>.acesso em 21. Mar.2018

BRASIL, República Federativa do. Consolidação das leis do trabalho. Promulgada em de 10 de maio de 1943. Disponível em < http://www.planalto.gov.br/ccivil_03/decreto-lei/del5452.htm>.acesso em 03 Ago. De 2018

DELGADO, Mauricio Godinho. Curso de direito do trabalho. 15. ed. ver. e atual. São Paulo: LTr. 2016, p. 300-310.

FRANÇA, República. Declaração universal de direitos humanos. Disponível em < http://www.onu.org.br/img/2014/09/DUDH.pdf>. Acesso em 09 Ago. 2018.

MARTINS, Flademir Jerônimo Belinati. Dignidade da pessoa humana: princípio constitucional fundamental. Curitiba: Juruá, 2011, p. 59.

PIOVESAN, Flávia. Direitos humanos: O princípio da dignidade da pessoa humana e a Constituição de 1988, 2004.

SARLET, Ingo Wolfgang. A eficácia dos direitos fundamentais. 10a ed. Porto Alegre: Livraria do Advogado, 2015, p.70.

SILINGOVSCHI, R.R.L.et al. Normas e padrões para trabalhos acadêmicos e científicos da Unoeste. Presidente Prudente: Unoeste. 2015.

SILVA, Jose Afonso da. A dignidade da pessoa humana como valor supremo da democracia. In: Revista de Direito Administrativo, 1998, p.89. 